\title{
ANÁLISE ERGONÔMICA DOS POSTOS DE TRABALHO EM UM ESCRITÓRIO E SUA INFLUÊNCIA NO CONFORTO DOS PROFISSIONAIS
}

\author{
OLIVEIRA,Sara Barroso de; \\ Faculdade Ateneu, Especialista em Engenharia de Segurança do Trabalho \\ e-mail:sarabarroso33@hotmail.com \\ NETO, Francisco Paulo do Nascimento; \\ Faculdade Ateneu, Especialista em Engenharia de Segurança do Trabalho \\ e-mail:paulonetotst@gmail.com
}

\begin{abstract}
RESUMO
Doenças ocupacionais podem ser adquiridas devido à exposição recorrente de indivíduos a agentes prejudiciais à sua saúde no local de trabalho. Riscos ergonômicos relacionam-se a fatores inerentes à atividade como: inadequação do mobiliário à anatomia do trabalhador, esforços físicos intensos e repetitividade ao longo da jornada. Foram analisados os riscos ergonômicos no trabalho de profissionais de um escritório em Fortaleza. Avaliaram-se quantitativamente a iluminação e o conforto térmico e qualitativamente a adequação do mobiliário do escritório. Constatou-se o impacto positivo da utilização de mobiliário ajustável, contudo é necessário o acompanhamento periódico do trabalhador para evitar comportamentos prejudiciais à sua saúde.
\end{abstract}

Palavras-chave: Trabalho; Ergonomia; Escritório.

\begin{abstract}
Occupational diseases can be acquired due to recurrent exposure of individuals to agents harmful to their health in the workplace. Ergonomic risks are related to factors inherent to the activity such as: inadequacy of furniture to the worker's anatomy, intense physical effort and repetitiveness throughout the day. Ergonomic risks were analyzed in the work of professionals from an office in Fortaleza. The lighting and the thermal comfort were quantitatively evaluated and the suitability of the office furniture was qualitatively evaluated. The positive impact of the use of adjustable furniture was verified, however, it is necessary the periodic monitoring of the worker to avoid behaviors detrimental to his health.
\end{abstract}

Keywords: Work; Ergonomics; Office.

\section{INTRODUÇÃO}

Doenças ocupacionais são adquiridas de diversas maneiras nos ambientes de trabalho devido à exposição de trabalhadores a riscos físicos, químicos, biológicos, ergonômicos e de acidentes, provocando muitas vezes consequências graves como invalidez ou morte do indivíduo. Trabalhadores de escritórios estão sujeitos principalmente a agravos de caráter ergonômico decorrentes de má postura, da realização de movimentos repetitivos e de inadequações anatômicas do indivíduo ao mobiliário de trabalho. 
Villarouco e Andreto (2008) enfatizam que para a criação de um espaço de trabalho que atenda às características de usabilidade, é importante avaliar os fatores que levam à obtenção de uma qualidade ambiental satisfatória e que caso os ambientes laborais sejam mal projetados, eles poderão gerar uma carga insalubre sobre os aspectos físicos, psicológicos e sociais, afetando a produtividade.

A NBR ISO-CIE 8995-1 da ABNT (Associação Brasileira de Normas Técnicas) estabelece que a iluminação deve satisfazer os aspectos qualitativos e quantitativos exigidos pelo ambiente. Já a norma NBR 10152 da ABNT, que fixa os níveis de ruído compatíveis com o conforto acústico em ambientes diversos, estabelece a faixa de ruído de $30 \mathrm{db}(A)$ a $40 \mathrm{db}(A)$ como adequado para ambientes de escritórios como salas de reunião. A ergonomia aborda também o caráter psicológico (ergonomia cognitiva) e o normativo (ergonomia organizacional) das condições de trabalho.

Este estudo objetiva a avaliação os riscos à saúde dos trabalhadores em relação aos aspectos ergonômicos enfatizando os requisitos posturais e ambientais, que em conjunto, contribuem para proporcionar mais bem estar ao indivíduo e resultados mais satisfatórios em relação ao trabalho executado.

\section{FUNDAMENTAÇÃO TEÓRICA}

Serão abordadas a seguir algumas definições de uma série de conceitos inerentes a este trabalho, sob o ponto de vista de diferentes autores, conforme elencado a seguir.

\subsection{Ambiente de Trabalho}

A Constituição Federal de 1988 em seus Art. 7ํ, XXXIII e Art. 200 definem meio ambiente do trabalho como "um conjunto de condições existentes no local de trabalho relativo à qualidade de vida do trabalhador." (AVILA; PRESTES, 2012).

\subsection{Análise Ergonômica do Trabalho}

"A análise ergonômica do trabalho permite identificar, por intermédio da observação do contexto real do trabalho, quais são as variáveis que o operador busca para compreender os problemas aos quais ele é confrontado e, desta forma, associar os processos cognitivos que ele mobiliza na execução do seu trabalho." (ABRAHÃO, 2000).

Segundo Villarouco e Andreto (2008) "uma completa avaliação ergonômica do ambiente abrange um vasto leque de variáveis composto pelos elementos da Antropometria, da Percepção Ambiental, da Ergonomia Cognitiva e da Análise Ergonômica do Trabalho (AET), assim como conceitos de conforto térmico, acústico e lumínico e acessibilidade integral".

\subsection{Ergonomia}

"A Ergonomia corresponde a uma disciplina científica que estuda o relacionamento entre o homem e sua atividade laboral, analisando a interação do mesmo e os equipamentos por ele utilizados no seu ambiente de trabalho." (VASCONCELOS; VILLAROUCO; SOARES, 2009).

\section{METODOLOGIA DE ESTUDO}

Para realizar o presente estudo, utilizou-se a metodologia RULA (rapid upper limb assessment) em um escritório que presta serviços advocatícios e que contém oito trabalhadores

Os equipamentos selecionados para as aferições quantitativas foram: decibelímetro para a medição de ruído, da marca INSTRUTHERM modelo DEC-300, luxímetro para determinação do iluminamento, da marca INSTRUTHERM modelo ITLX801 e uma trena de marca vonder com cinquenta metros de comprimento. 
O método RULA (Rapid Upper Limb Assessment) faz uma análise postural que fornece um resultado numérico e a classificação dos níveis dos riscos em que haja a possibilidade de desenvolvimento de lesões por esforços repetitivos em membros superiores e inferiores.

As avaliações qualitativas foram efetuadas baseando-se na observação das atividades desenvolvidas no local de trabalho analisando, bem como as características do ambiente, as peculiaridades operacionais e a agressividade potencial dos agentes considerados.

Em posse das tabelas de comparação fornecidas a seguir, realizaram-se os seguintes passos na obtenção dos resultados para cada setor: compararam-se as pontuações do braço com a do antebraço, com a do punho e a de rotação do punho. A maior pontuação foi considerada para o cálculo (pontuação A). Compararam-se as pontuações do pescoço, das pernas e do tronco. A maior pontuação foi considerada para o cálculo. (pontuação B)

Em seguida, utilizaram-se as seguintes equações:

Pontuação A + pontuação esforço muscular + pontuação da carga = resultado A [Eq.01]

Pontuação B + pontuação esforço muscular + pontuação da carga = resultado B [Eq.02]

Compararam-se os resultados A e B. O maior resultado prevaleceu e foi considerado como pontuação final. Utilizaram-se as tabelas apresentadas a seguir empregadas pela metodologia RULA como parâmetro de avaliação postural dos trabalhadores em estudo.

\begin{tabular}{|l|c|c|c|c|c|}
\hline \multicolumn{5}{c}{ Tabela 01 - Pontuação Para Os Braços - Método RULA } \\
\hline Pontuação & 1 & 2 & 3 \\
\hline
\end{tabular}

Adaptado de MCATAMNEY \& CORLETT (1993).

Tabela 02 - Pontuação Para Os Antebraços - Método RULA

\begin{tabular}{|c|c|c|c|}
\hline Pontuação & 1 & 2 & $\begin{array}{c}\text { Acrescentar } \\
+1 \text { se o braço } \\
\text { cruzar a linha } \\
\text { Posição }\end{array}$
\end{tabular}

Adaptado de MCATAMNEY \& CORLETT (1993). 
Tabela 03 - Pontuação Para Os Punhos - Método RULA

\begin{tabular}{|c|c|c|c|c|c|}
\hline Pontuação & 1 & 2 & 3 & & \\
\hline Posição & & & & $\begin{array}{c}+1 \text { se } \\
\text { Houver } \\
\text { desvio da } \\
\text { linha neutra. }\end{array}$ & Plph \\
\hline
\end{tabular}

Adaptado de MCATAMNEY \& CORLETT (1993).

Tabela 04 - Pontuação Para O Giro do Punho - Método RULA

\begin{tabular}{|c|c|c|}
\hline Pontuação & 1 & 2 \\
\hline Característica do giro do punho & $\begin{array}{c}\text { Principalmente na } \\
\text { metade da amplitude } \\
\text { de giro do punho }\end{array}$ & $\begin{array}{c}\text { No início ou final da amplitude } \\
\text { de giro do punho }\end{array}$ \\
\hline \multicolumn{2}{|c|}{ Adaptado de MCATAMNEY \& CORLETT (1993). }
\end{tabular}

Tabela 05 - Pontuação Para a Inclinação do Pescoço - Método RULA

\begin{tabular}{|c|c|c|c|}
\hline Pontuação & 1 & 2 & \\
\hline Posição & +1 se houver giro do pescoço \\
\hline Acrescentar & +1 se houver inclinação lateral do pescoço \\
\hline
\end{tabular}

Adaptado de MCATAMNEY \& CORLETT (1993).

Tabela 06- Pontuação Para a Inclinação do Tronco - Método RULA

\begin{tabular}{|c|c|c|c|c|}
\hline Pontuação & 1 & 2 & 3 & 4 \\
\hline \multicolumn{5}{|l|}{ Posição } \\
\hline Acrescentar & & ho & ate & \\
\hline
\end{tabular}

Adaptado de MCATAMNEY \& CORLETT (1993).

Tabela 07 - Pontuação Para a Posição das Pernas - Método RULA

\begin{tabular}{|c|c|c|}
\hline Pontuação & 1 & 2 \\
\hline $\begin{array}{c}\text { Extremidades } \\
\text { inferiores }\end{array}$ & $\begin{array}{c}\text { Se as pernas e os pés estão } \\
\text { bem apoiados e equilibrados }\end{array}$ & $\begin{array}{c}\text { Se as pernas e os pés não estão } \\
\text { corretamente apoiados e equilibrados }\end{array}$ \\
\hline
\end{tabular}

Adaptado de MCATAMNEY \& CORLETT (1993).

Tabela 08 - Pontuação para Esforço Muscular - Método RULA

Se a postura é principalmente estática (mantida por mais de 10 minutos) ou

Acrescentar +1

Se existe atividade repetitiva (4 vezes por minuto ou mais)

Adaptado de MCATAMNEY \& CORLETT (1993). 
Tabela 09 - Pontuação para o Levantamento de Carga - Método RULA

\begin{tabular}{|c|c|c|c|c|}
\hline Carga & $\begin{array}{c}\text { Menor que } \\
2 \mathrm{Kg} \\
\text { (intermitente) }\end{array}$ & $\begin{array}{c}2 \mathrm{a} 10 \mathrm{Kg} \\
\text { (intermitente) }\end{array}$ & $\begin{array}{c}2 \mathrm{a} 10 \mathrm{Kg} \\
\text { (estático ou } \\
\text { repetido) }\end{array}$ & $\begin{array}{c}\text { Maior que } \\
10 \mathrm{Kg} \text { ou } \\
\text { repetida ou de } \\
\text { impacto }\end{array}$ \\
\hline Acrescentar & +0 & +1 & +2 & +3 \\
\hline
\end{tabular}

Adaptado de MCATAMNEY \& CORLETT (1993).

Para o emprego da Metodologia RULA, utilizou-se como instrumento de avaliação as tabelas 01 a 09 acima apresentadas e foi considerada, para a interpretação de seus resultados, a tabela 10 .

Tabela 10 - Referências para a Interpretação dos Resultados

\begin{tabular}{|c|c|c|}
\hline Pontuação & Pontos & Resultados \\
\hline Nível 1 & 1 ou 2 & $\begin{array}{c}\text { Postura aceitável, se não for mantida ou repetida por longos } \\
\text { períodos de tempo. }\end{array}$ \\
\hline Nível 2 & 3 ou 4 & Postura a investigar e poderão ser necessárias alterações \\
\hline Nível 3 & 5 ou 6 & Postura a investigar e alterar rapidamente \\
\hline Nível 4 & 7 ou mais & Postura a investigar e alterar urgentemente \\
\hline
\end{tabular}

Adaptado de MCATAMNEY \& CORLETT (1993).

Com a realização das medições dos parâmetros ambientais com o luxímetro e o decibelímetro e a observação da posição e dos movimentos de trabalho em comparação com a pontuação estabelecida pelo método RULA, obteve-se os resultados descritos nos próximos itens.

\section{RESULTADOS E DISCUSSÕES}

A implementação dos procedimentos acima referidos permitiram a obtenção dos resultados elencados a seguir:

\subsection{Local De Trabalho - Recepção}

\subsubsection{Descrição Do Ambiente}

Sala com paredes em alvenaria com área de $3,00 \mathrm{~m}^{2}$, cobertura de gesso, piso cerâmico, pé-direito de 2,50 m, ventilação artificial por meio de ar condicionado, iluminação artificial por meio de luminárias com lâmpadas fluorescentes uniformemente distribuídas.

\subsubsection{Mobiliário e Equipamentos Instalados e Utilizados}

A sala possuía os seguintes móveis e equipamentos: um notebook; um televisor, um telefone, um ar condicionado, duas cadeiras com rodízios, duas mesas de trabalho e um armário.

\subsubsection{Número de Trabalhadores Expostos e Funções}

Um auxiliar administrativo.

\subsubsection{Descrição da Atividade}

Realiza serviços administrativos, recepciona os clientes, elabora relatórios diários, controle e registros das atividades de acordo com as necessidades dos advogados, controla os registros de frequência e demais atividades referentes ao setor de administração. $A$ tabela 11 especifica as observações relatadas neste ambiente bem como sua adequação quanto à NR-17 - Norma Regulamentadora no 17 do Ministério do Trabalho. 
Tabela 11 - Resultado Obtido das Condições Ergonômicas de Trabalho - Recepção

\begin{tabular}{|c|c|c|c|}
\hline $\begin{array}{c}\text { Ambiente de } \\
\text { trabalho e } \\
\text { atividade exercida }\end{array}$ & $\begin{array}{l}\text { Situação } \\
\text { Verificada }\end{array}$ & $\begin{array}{l}\text { Previsão Normativa } \\
\text { (NR } 17^{*} \text { e subitens) }\end{array}$ & $\begin{array}{l}\text { Condição } \\
\text { Ergonômica }\end{array}$ \\
\hline Postura de trabalho & Postura sentada & $\begin{array}{l}\text { O posto de trabalho deve } \\
\text { ser planejado ou } \\
\text { adaptado para a posição } \\
\text { sentada. }\end{array}$ & Adequada \\
\hline Toques no teclado & $\begin{array}{c}\text { Em média } 3.000 \\
\text { toques }\end{array}$ & $\begin{array}{c}\text { Número máximo de } \\
\text { toques: } 8.000 / \text { hora } \\
\text { trabalhada. }\end{array}$ & Adequada \\
\hline Mesa & $\begin{array}{l}74 \mathrm{~cm} \text { de altura, } \\
\text { permite espaço } \\
\text { suficiente para os } \\
\text { materiais e } \\
\text { posicionamento } \\
\text { adequado dos } \\
\text { segmentos } \\
\text { corporais }\end{array}$ & $\begin{array}{l}\text { Altura da superfície de } \\
\text { trabalho compatível com } \\
\text { a atividade e com a altura } \\
\text { do assento. } \\
\text { Área de fácil alcance e } \\
\text { visualização do } \\
\text { trabalhador e que } \\
\text { possibilite o } \\
\text { posicionamento } \\
\text { adequado dos } \\
\text { segmentos corporais. }\end{array}$ & Adequada \\
\hline Cadeira & $\begin{array}{l}\text { Revestida em } \\
\text { tecido, bordas } \\
\text { arredondadas, com } \\
\text { regulagem de } \\
\text { altura do assento, } \\
\text { encosto firme para } \\
\text { coluna. }\end{array}$ & $\begin{array}{c}\text { NR 17.3.3- altura } \\
\text { ajustável ao trabalhador, } \\
\text { borda anterior } \\
\text { arredondada, encosto } \\
\text { com forma adaptada para } \\
\text { a proteção da coluna. }\end{array}$ & Adequada \\
\hline Apoio para os pés & $\begin{array}{l}\text { Uso do apoio para } \\
\text { pés ou pés } \\
\text { apoiados no chão } \\
\text { confortavelmente }\end{array}$ & $\begin{array}{c}\text { Melhor apoio dos } \\
\text { membros inferiores e } \\
\text { acomodação da coluna } \\
\text { lombar no encosto da } \\
\text { cadeira }\end{array}$ & Adequada \\
\hline Ruído & $49,5 \mathrm{~dB}(\mathrm{~A})$ & $\begin{array}{c}\text { NR 17.5.2- de acordo } \\
\text { com a NBR } \\
10152 \text { (entre } 45 \text { e } 65 \mathrm{~dB} \\
\text { (A)) }\end{array}$ & Adequada \\
\hline $\begin{array}{c}\text { Nível de } \\
\text { iluminamento }\end{array}$ & 507 lux & $\begin{array}{c}\text { De acordo com NBR } \\
5413 \text { (500 a } 1000 \text { lux }) \text {. }\end{array}$ & Adequado \\
\hline Temperatura & $21^{\circ} \mathrm{C}$ & $\begin{array}{c}\text { NR } 17.5 .2-\text { entre } 20 \mathrm{e} \\
23^{\circ} \mathrm{C} .\end{array}$ & Adequado \\
\hline Velocidade do ar & Inferior a $0,75 \mathrm{~m} / \mathrm{s}$ & $\begin{array}{c}\text { NR 17.5.2- não superior } \\
\text { a } 0,75 \mathrm{~m} / \mathrm{s} .\end{array}$ & Adequado \\
\hline
\end{tabular}


Umidade relativa do ar

NR 17.5.2- não inferior a $40 \%$.

Adequado

A análise dos membros da postura obteve como resultado a pontuação 03 , para os membros superiores e a pontuação 02 para os membros inferiores. Não foi adicionada nenhuma pontuação para a carga nem para o músculo. O somatório das pontuações dos membros inferiores e superiores chegaram à pontuação final de 03 , que, segundo a técnica do método RULA, significa postura a investigar e poderão ser necessárias alterações.

\subsection{Local de Trabalho: Escritório do Advogado}

\subsubsection{Descrição do Ambiente}

Sala com paredes em alvenaria com área de $4,00 \mathrm{~m}^{2}$, cobertura de gesso, piso cerâmico, pé-direito de $2,50 \mathrm{~m}$, ventilação artificial por meio de aparelho de ar condicionado, iluminação artificial por meio de luminárias com lâmpadas fluorescentes uniformemente distribuídas.

\subsubsection{Mobiliário e Equipamentos Instalados e Utilizados}

A sala em análise continha os seguintes equipamentos e mobiliário: um notebook, um telefone, uma cadeira com rodízios, uma mesa de computador e trabalho, uma prateleira, um armário, uma impressora.

\subsubsection{Número de Trabalhadores Expostos e Funções Exercidas}

Um advogado.

\subsubsection{Descrição Da Atividade}

Postulam, em nome do cliente, em juízo, propondo ou contestando ações, solicitando providências junto ao magistrado ou ministério público, avaliando provas, realizando audiências trabalhista, penais, comuns e cíveis, mediando questões, assistindo empresas, pessoas e entidades, assessorando negociações e outras atividades correlatas.

A tabela 12 especifica as observações relatadas neste ambiente bem como sua adequação quanto às normas brasileiras concernentes à Ergonomia.

Tabela 12 - Resultado Obtido das Condições Ergonômicas de Trabalho - Sala do Advogado

\begin{tabular}{|c|c|c|c|}
\hline $\begin{array}{c}\text { Ambiente de } \\
\text { Trabalho e } \\
\text { Atividade } \\
\text { Exercida }\end{array}$ & $\begin{array}{c}\text { Situação } \\
\text { Verificada }\end{array}$ & $\begin{array}{c}\text { Previsão Normativa } \\
\text { NR-17* }\end{array}$ & $\begin{array}{c}\text { Condição } \\
\text { Ergonômica }\end{array}$ \\
\hline & & & \\
\hline $\begin{array}{c}\text { Postura de } \\
\text { Trabalho }\end{array}$ & Postura sentada & $\begin{array}{l}\text { O posto de trabalho } \\
\text { deve ser planejado ou } \\
\text { adaptado para a } \\
\text { posição sentada }\end{array}$ & Adequada \\
\hline $\begin{array}{c}\text { Toques no } \\
\text { Teclado }\end{array}$ & $\begin{array}{c}\text { Em média } \\
\text { Não devem exceder } \\
8000 / \text { hora }\end{array}$ & \\
\hline
\end{tabular}




\begin{tabular}{|c|c|c|c|}
\hline $\begin{array}{l}\text { Tempo de } \\
\text { atividade em } \\
\text { computador }\end{array}$ & Máximo 4 horas/dia & $\begin{array}{c}\text { Não devem exceder } \\
5 \mathrm{~h} / \text { dia. }\end{array}$ & Adequada \\
\hline Mesa & $\begin{array}{l}\text { Altura de } 74 \mathrm{~cm} \text {, } \\
\text { Não impedia } \\
\text { movimentos dos } \\
\text { membros inferiores } \\
\text { do trabalhador. }\end{array}$ & $\begin{array}{l}\text { Altura da superfície de } \\
\text { trabalho compatível } \\
\text { com a atividade } \\
\text { exercida e com a } \\
\text { altura do assento. } \\
\text { Possibilitar o } \\
\text { posicionamento } \\
\text { adequado dos } \\
\text { segmentos corporais }\end{array}$ & Adequada \\
\hline Cadeira & $\begin{array}{l}\text { Com rodízios, altura } \\
\text { ajustável na base } \\
\text { do assento, } \\
\text { revestida de } \\
\text { espuma no assento } \\
\text { e espaldar e bordas } \\
\text { arredondadas. }\end{array}$ & $\begin{array}{l}\text { Altura ajustável ao } \\
\text { trabalhador, borda } \\
\text { anterior arredondada, } \\
\text { encosto com forma } \\
\text { adaptada para } \\
\text { proteger a coluna do } \\
\text { trabalhador. }\end{array}$ & Adequada \\
\hline Apoio para os pés & $\begin{array}{c}\text { Base de apoio para } \\
\text { os pés disponível e } \\
\text { eventualmente } \\
\text { utilizada. }\end{array}$ & $\begin{array}{l}\text { Melhor apoio dos } \\
\text { membros inferiores e } \\
\text { acomodação da } \\
\text { coluna lombar no } \\
\text { encosto da cadeira. }\end{array}$ & Adequada \\
\hline Ruído & $50 \mathrm{~dB}(\mathrm{~A})$ & $\begin{array}{c}\text { Entre } 45 \mathrm{~dB}(\mathrm{~A}) \text { e } 65 \\
\mathrm{~dB}(\mathrm{~A})^{* *}\end{array}$ & Adequada \\
\hline Luminosidade & 730 Lux & $\begin{array}{c}\text { Entre } 500 \operatorname{lux}_{\operatorname{lux}}^{* * *} 1000 \\
\end{array}$ & Adequada \\
\hline Temperatura & $22^{\circ} \mathrm{C}$ & Entre $20^{\circ} \mathrm{C}$ e $23^{\circ} \mathrm{C}$ & Adequada \\
\hline Umidade Relativa & $73 \%$ & Não inferior a $40 \%$ & Adequada \\
\hline
\end{tabular}

*Norma Regulamentadora № 17 do Ministério do Trabalho e Previdência Social.

${ }^{*}$ De acordo com a norma ABNT NBR 10152:2011

*** De acordo com a norma ABNT NBR 5312: 2009.

A análise dos membros da postura obteve como resultado a pontuação 02 , tanto para os membros inferiores quanto para os superiores. Onde não foi adicionada nenhuma pontuação para a carga nem para o músculo. O somatório das pontuações dos membros inferiores e superiores chegaram à pontuação final de 02 , que segundo a técnica do Método RULA a Postura é aceitável, se não for mantida ou repetida por longos períodos de tempo.

Os resultados obtidos condizem com o esperado para o trabalho em ambientes de escritório, uma vez que as atividades neles executadas raramente envolvem a necessidade de tarefas com levantamento de carga, em contrapartida, requerem longos períodos da jornada laboral com postura estática e operações de digitação em computador.

Entretanto a aquisição de mobiliário adequado ao indivíduo não é suficiente para a garantia de sua perfeita saúde, havendo a necessidade da adoção de medidas adicionais que contribuem para a sua qualidade de vida no trabalho. Uma das medidas que pode ser mencionada é a ginástica laboral. OLIVEIRA, J.R.G. afirma em seu estudo que, em média, após três a doze meses de implantação, a ginástica laboral demonstra seus benefícios, como: redução dos casos de LER/DORT, menores custos com assistência médica, alívio de dores corporais, diminuição do absenteísmo, mudanças no estilo de vida e, consequentemente, aumento de produtividade. 


\section{CONCLUSÕES}

A realização deste estudo permitiu constatar que apesar de não haver exigência contínua da realização de esforço físico intenso nas atividades de trabalhadores de escritório, ainda há a possibilidade do desencadeamento de doenças ocupacionais provenientes de agentes de risco ergonômico a estes indivíduos. A seleção de mobiliário ajustável e ergonomicamente adequado aos indivíduos do escritório apresentou considerável importância com medida preventiva do desenvolvimento dessas doenças, entretanto, não deve ser a única estratégia adotada, recomendando-se o acréscimo de outras ações, como a ginástica laboral, com fins de proporcionar melhoria contínua na saúde e qualidade de vida dos trabalhadores.

\section{REFERÊNCIAS BIBLIOGRÁFICAS}

ABRAHÃO, Júlia Issy. Reestruturação Produtiva e Variabilidade do Trabalho: Uma Abordagem da Ergonomia. Revista Psicologia: Teoria e Pesquisa, v. 16, n. 1, p. 49 - 54, abr. 2000.

ABNT. ASSOCIAÇÃO BRASILEIRA DE NORMAS TÉCNICAS. NBR ISO-CIE 8995-1.2013 lluminação de Ambientes de Trabalho. Disponível em: <http://pt.scribd.com/doc/148302497/Abnt-Nbr-Iso-cie-8995-1\#scribd>. Acesso em: 12 ago. 2015.

ABNT. ASSOCIAÇÃO BRASILEIRA DE NORMAS TÉCNICAS. NBR 10152 - Níveis de Ruído para Conforto Acústico. Disponível em: <http://www.prefeitura.sp.gov.br/cidade/secretarias/upload/esportes/norma\%20abnt\%201015 2.pdf>. Acesso em: 12 ago. 2015.

ÁVILA, Simone Aparecida de; PRESTES, Lígia Bonete. Ambiente de Trabalho: Com ênfase em ergonomia no escritório. Revista de Ciências Jurídicas e Sociais, Guarulhos, v. 2, n. 1 , p.55-60, 2012.

BRAGA, Celso de Oliveira; ABRAHÃO, Roberto Funnes; TERESO, Mauro José Andrade. Análise Ergonômica do Trabalho em Unidades de Beneficiamento de Produtos Agrícolas: Exigências Laborais dos Postos de Seleção. Revista Ciência Rural, Santa Maria, v. 39, n. 8, p.1552-1557, ago. 2009.

BRASIL. Portaria GM no 3.214 de 08 de junho de 1978. Norma Regulamentadora № 17 Ergonomia. Ministério do Trabalho e Previdência Social. Disponível em: < http://trabalho.gov.br/images/Documentos/SST/NR/NR17.pdf >. Acesso em: 23 de Junho de 2017 às 13 h20.

CANELLAS, Kátia Virgínia; FORCELLINI, Francieli; ODEBRECHT,Clarisse. Evolução dos Postos de Trabalho: Aspectos Ergonômicos dos Escritórios em Blumenau-SC. Disponível em:

$<$ http://fido.palermo.edu/servicios dyc/encuentro2007/02 auspicios publicaciones/actas dis eno/articulos pdf/A7011.pdf >. Acesso em: 19 jun.2015.

JUNIOR, Almir Mariano de Souza et al. Análise Ergonômica do Trabalho e Aplicação do Método RULA: Um Estudo de Caso no Serviço de Limpeza de Logradouros Públicos. XXX Encontro Nacional de Engenharia de Produção. São Carlos- SP, Brasil. 2010.

LIMA, Johnson Brito de; CRUZ, Gleice Araújo da. Trabalho Sentado: Riscos Ergonômicos para Profissionais de Bibliotecas, Arquivos e Museus. Revista Brasileira de Arqueometria, Restauração e Conservação - Arc, Olinda, v. 3, n. 1, p.150-157, set. 2011.

MCATAMNEY, L; CORLETT, E.N; RULA: A survey method for the investigation of worldrelated upper limb disorders. Applied Ergonomics, v. 24, n. 2, p. 91-99, 1993. 
OLIVEIRA, João Ricardo Gabriel de. A importância da Ginástica Laboral na Prevenção de Doenças Ocupacionais. Revista de Educação Física. v. 1, n. 139, p. 40-48, dez. 2007.

PRZYSIEZNY, Wilson Luiz. Distúrbios Osteomusculares Relacionados ao Trabalho: um enfoque ergonômico. Dynamis, v. 31, n. 8, p.19-34, 2000.

PAINI, Anderson da Costa; LOPES, Eduardo da Silva; OLIVEIRA, Felipe Martins de. Postura Corporal de Operador no Carregamento Mecanizado de Madeira: Estudo de Caso. Enciclopédia Biosfera - Centro Científico Conhecer, Goiânia, v. 13, n. 23, p. 962- 974.

SOARES, Marcelo. Ergonomia: soluções e propostas para um trabalho melhor. Production, [s.I.], v. 19, n. 3, p.1-3, 2009. FapUNIFESP (SciELO). http://dx.doi.org/10.1590/s010365132009000300001 .

SOUZA, Bianca Cristina Conceição de; JÓIA, Luciane Cristina. Relação entre Ginástica Laboral e Prevenção das Doenças Ocupacionais: Um estudo Teórico. Conquer, v. 1, 2006. Disponível em: <http://www.fasb.edu.br/revista/index.php/conquer> Acesso em: ago.2015.

VILLAROUCO, Vilma; ANDRETO, Luiz F. M. Avaliando desempenho de espaços de trabalho sob o enfoque da ergonomia do ambiente construído. Revista Produção, Recife, v. 18, n. 3, p.523-539, set. 2008.

VASCONCELOS, Christianne Soares Falcão e; VILLAROUCO, Vilma; SOARES, Marcelo Márcio. Avaliação Ergonômica do Ambiente Construído: estudo de caso em uma biblioteca universitária. Ação Ergonômica, Recife, v. 4, n. 1, p.5-25, 2009. 